\title{
Human Papillomavirus Type 16 E6/E7-Specific Cytotoxic T Lymphocytes for Adoptive Immunotherapy of HPV-Associated Malignancies
}

\author{
Carlos A. Ramos ${ }^{1,2}$, Neeharika Narala ${ }^{1}$, Gayatri M. Vyas ${ }^{1}$, Ann M. Leen ${ }^{1,3}$, Ulrike \\ Gerdemann $^{1}$, Erich M. Sturgis ${ }^{7,8}$, Matthew L. Anderson ${ }^{4,5}$, Barbara Savoldo ${ }^{1,3}$, Helen E. \\ Heslop $^{1,2,3}$, Malcolm K. Brenner ${ }^{1,2,3}$, and Cliona M. Rooney ${ }^{1,3,5,6}$ \\ ${ }^{1}$ Center for Cell and Gene Therapy, Baylor College of Medicine, The Methodist Hospital and \\ Texas Children's Hospital, Houston, TX, USA. \\ ${ }^{2}$ Department of Medicine, Baylor College of Medicine, Houston, TX, USA. \\ ${ }^{3}$ Department of Pediatrics, Baylor College of Medicine, Houston, TX, USA. \\ ${ }^{4}$ Department of Gynecology and Obstetrics, Baylor College of Medicine, Houston, TX, USA. \\ ${ }^{5}$ Department of Pathology and Immunology, Baylor College of Medicine, Houston, TX, USA. \\ ${ }^{6}$ Department of Molecular Virology and Microbiology, Baylor College of Medicine, Houston, TX, \\ USA. \\ ${ }^{7}$ Department of Head and Neck Surgery, the University of Texas MD Anderson Cancer Center, \\ Houston, TX, USA. \\ ${ }^{8}$ Department of Epidemiology, the University of Texas MD Anderson Cancer Center, Houston, \\ TX, USA.
}

\section{Abstract}

\begin{abstract}
Vaccines prevent HPV-associated cancer but, although these tumors express foreign, viral antigens (E6 and E7 proteins), they have little benefit in established malignancies, likely due to negative environmental cues that block tumor recognition and induce T cell anergy in vivo. We postulated that we could identify mechanisms by which ex vivo stimulation of T cells could reactivate and expand tumor-directed T-cell lines from HPV-positive cancer patients for subsequent adoptive immunotherapy.
\end{abstract}

A total of 68 patients with HPV-associated cancers were studied. Peripheral blood T cells were stimulated with monocyte-derived dendritic cells loaded with pepmixes (peptide libraries of 15mers overlapping by 11 amino-acids) spanning E6/E7, in the presence or absence of specific accessory cytokines. The resulting T-cell lines were further expanded with pepmix-loaded activated B-cell blasts. IFN $\gamma$ release and cytotoxic responses to E6/E7 were assessed.

Corresponding author: Carlos A. Ramos, MD, Assistant Professor of Medicine, Center for Cell and Gene Therapy, Department of Medicine, Baylor College of Medicine, One Baylor Plaza BCM 505, Houston, TX 77030, caramos@ bcm.edu, Phone: 832-824-4817, Fax: 832-825-4732.

Publisher's Disclaimer: This is a PDF file of an unedited manuscript that has been accepted for publication. As a service to our customers we are providing this early version of the manuscript. The manuscript will undergo copyediting, typesetting, and review of the resulting proof before it is published in its final citable form. Please note that during the production process errors may be discovered which could affect the content, and all legal disclaimers that apply to the journal pertain.

Financial Disclosure: All authors have declared there are no financial conflicts of interest in regards to this work. 
We successfully reactivated and expanded (>1200-fold) E6/E7-specific T cells from 8/16 cervical and 33/52 oropharyngeal cancer patients. The presence of the cytokines IL-6, $-7,-12$ and -15 is critical for this process. These $\mathrm{T}$ cell lines possess the desirable characteristics of polyclonality, multiple $\mathrm{T}$-cell subset representation (including the memory compartment) and a $\mathrm{T}_{\mathrm{H}} 1$ bias, and may eliminate E6/E7-positive targets.

In conclusion, we have shown it is possible to robustly generate HPV16 E6/E7-directed T-cell lines from patients with HPV16-associated cancers. Because our technique is scalable and goodmanufacturing-procedures compliant, these lines could be used for adoptive cellular immunotherapy of patients with HPV16-positive cancers.

\section{Introduction}

Of the more than 100 known serotypes of human papillomavirus (HPV), one - HPV16 - is strongly associated with squamous cell carcinomas of the anogenital tract and oropharynx,,${ }^{1-6}$ being found in approximately $50 \%$ of cervical, ${ }^{4} 70 \%$ anal, ${ }^{7} 30 \%$ penile $^{8}$ and $>75 \%$ of base-of-tongue and tonsillar cancers. ${ }^{4}$ In the US alone, more than 40,000 new cases of these cancers are diagnosed annually. ${ }^{9}$ While many HPV-associated tumors can be eradicated by multimodality therapy, recurrent disease has an extremely poor prognosis, ${ }^{10,11}$ and although HPV vaccines are effective at preventing many of these cancers, they have no activity against established neoplasms.

HPV 16 has a small genome of approximately $8 \mathrm{~kb}$, which is organized into early coding, late coding, and long control regions. ${ }^{12}$ Proviral integration into host DNA is critical for oncogenesis, and leads to uncontrolled production of the transforming proteins E6 and E7, which bind $\mathrm{p} 53$ and $\mathrm{pRb}$, causing their degradation or inactivation. This leads to genetic instability of the cell and carcinogenesis. ${ }^{13}$ At this point, the structural proteins L1 and L2, the targets of the current HPV vaccines, are no longer expressed. Despite continued expression of the viral antigens E6 and E7, however, it has proved challenging to elicit robust immune responses against those antigens in patients with HPV-associated cancers. ${ }^{12-15}$ E6/E7-specific precursor cells may be rare and difficult to expand in vivo because immune-inhibitory cues in the tumor environment may block initial tumor cell recognition, and subsequent $\mathrm{T}$ cell activation, expansion, or persistence.

We have recently shown that cytotoxic T lymphocytes (CTLs) directed even to weak tumor associated antigens can be generated from patients' peripheral blood T cells in vitro by the addition of cytokines that reverse anergy, inhibit expansion of regulatory $\mathrm{T}$ cells (Tregs) and promote effector $\mathrm{T}$ cell survival. ${ }^{16,17}$. We postulated that we could identify similar mechanisms to reactivate $\mathrm{T}$ cells specific for cancer-associated HPV antigens. For these cells to be useful as a therapy for patients with HPV-associated malignancies, they must be expanded to numbers sufficient for administration whilst retaining representation of critical T-cell sub-populations, such as the effector and memory compartments required for persistence, and include cells with a cytotoxic $\mathrm{T}_{\mathrm{H}} 1$ phenotype. Additionally, they should be polyclonal and preferentially target multiple epitopes in E6 and E7 antigens to avoid tumor escape by loss of a single target epitope. Here, we describe a robust and GMP-compliant approach that, in the majority of patients studied, produces HPV16 E6/E7-directed T cells with the desired phenotype, number and function for adoptive transfer to patients with HPVassociated cancers. 


\section{Materials and Methods}

\section{Donors and cell lines}

Blood from healthy volunteers and patients with cervical and oropharyngeal cancers (nonmetastatic, stages II-IVA) was obtained after informed consent on protocols approved by Baylor College of Medicine and the University of Texas MD Anderson Cancer Center Institutional Review Boards. Peripheral blood mononuclear cells (PBMCs), isolated by gradient centrifugation (Lymphoprep; Axis-Shield, Oslo, Norway), were used to generate dendritic cells (DCs), T cell lines, and B-cell blasts (BB).

\section{HPV typing of tumor tissue}

When available, paraffin-embedded tumor tissue from the primary lesion or a nodal metastasis was assessed for the presence of HPV16 DNA. Whole sample DNA was isolated after digestion of the sample with proteinase $\mathrm{K}$, using standard procedures. A PCR assay was then utilized to amplify the HPV16 E7 region, using the primers 5'ATTAAATGACAGCTCAGAGGA-3' and 5'-GCTTTGTACGCACAACCGAAGC-3', which generate a 133-bp fragment. Southern blotting followed by hybridization with a labeled probe specific for HPV16 E7 was used to confirm the identity of the amplified fragment.

\section{Monocyte isolation and DC generation}

DCs were generated as previously described ${ }^{18}$ Briefly, monocytes were isolated from PBMCs by CD14 selection using MACS Beads (Miltenyi Biotec, Bergisch Gladbach, Germany) and cultured in 24-well plates $\left(1 \times 10^{6}\right.$ cells/well $)$ in DC medium, consisting of CellGenix medium (CellGenix USA, Antioch, IL) and $2 \mathrm{mM}$ alanyl-glutamine (GlutaMAX; Invitrogen, Carlsbad, CA), with $800 \mathrm{U} / \mathrm{mL}$ granulocyte/macrophage-colony stimulating factor (GM-CSF) (Leukine; Immunex, Seattle, WA) and 1,000 U/mL IL-4 (R\&D Systems, Minneapolis, MN) for 5 days. GM-CSF and IL-4 were replenished on day 3. On day 5, DCs were matured in DC media with $10 \mathrm{ng} / \mathrm{mL}$ IL-1 $\beta$ (R\&D Systems), $100 \mathrm{ng} / \mathrm{mL}$ IL-6 (R\&D Systems), $10 \mathrm{ng} / \mathrm{mL}$ tumor necrosis factor- $\alpha$ (TNFa) (R\&D Systems), $1 \mu \mathrm{g} / \mathrm{mL}$ prostaglandin E2 (Sigma, Saint Louis, MO), 800 U/mL GM-CSF and 1,000 U/mL IL-4. DC maturation was assessed by flow cytometry to detect upregulation of CD80, CD83, CD86 and HLA-DR.

\section{HPV16-E6 and -E7 peptide library}

Overlapping peptide libraries (15-mers overlapping by 11 amino acids), containing all possible HLA class I-restricted epitopes and many HLA class II-restricted epitopes of HPV16-E6 (UniProt Protein ID P03126) and HPV16-E7 (P03129), were purchased from JPT Technologies (Berlin, Germany). Peptide pools, containing mixtures of 4 to 7 individual peptides, and peptide mixtures (pepmixes), comprising all individual peptides for each antigen, were prepared. Peptides were dissolved in dimethyl sulfoxide (DMSO) at $5 \mathrm{mg} / \mathrm{mL}$.

\section{HPV16 E6/E7-specific (and Adenovirus/CMV-specific) T cell generation}

DCs were loaded with E6 and E7 pepmixes by incubating for $30-60 \mathrm{~min}$ at $37^{\circ} \mathrm{C}$ a pellet of mature DCs with $100 \mu \mathrm{L}$ of a 1:200 dilution of each pepmix solution in CTL medium, a 1:1 mixture of RPMI 1640 (Hyclone, Logan, UT) and Click's medium (Irvine Scientific, Santa Ana, CA) supplemented with 10\% human AB serum (Valley Biomedicals, Winchester, VA) and $2 \mathrm{mM}$ alanyl-glutamine. Excess peptide was then washed off by serial suspension in CTL medium and centrifugation. CD14-negative PBMCs were first stimulated with peptideloaded DCs at a stimulator-to-responder ( $\mathrm{S}: \mathrm{R})$ ratio of 1:10-20. Cells were cultured at a concentration of $1 \times 10^{6} / \mathrm{mL}$ in CTL medium $\left(2 \times 10^{6}\right.$ PBMCs per well of 24 -well plates $)$ with 
or without supplementation with $100 \mathrm{ng} / \mathrm{mL}$ IL-6, $10 \mathrm{ng} / \mathrm{mL}$ IL-7 (R\&D Systems), $10 \mathrm{ng} /$ $\mathrm{mL}$ IL-12 (R\&D Systems) and $10 \mathrm{ng} / \mathrm{mL}$ IL-15 (R\&D Systems). On day 9 or 10 , T cells were harvested, counted to assess viability using trypan blue exclusion, and further expanded at a concentration of $5 \times 10^{5} / \mathrm{mL}$ in CTL medium $\left(1 \times 10^{6} \mathrm{~T}\right.$ cells per well of $24-$ well plates) by a second stimulation at a $\mathrm{S}: \mathrm{R}$ ratio of 1:5-10 with freshly prepared pepmixloaded DCs. These co-cultures were supplemented with IL-2 (Proleukin; Chiron, Emeryville, CA) $50 \mathrm{U} / \mathrm{ml}$ on day 12 . One week after this second stimulation, CTLs were harvested, counted to assess viability using trypan blue exclusion, and used in phenotypic and functional assays or further expanded by weekly stimulation at a $S: R$ ratio of $1: 4$ with freshly prepared pepmix-loaded BB (see below), in the presence of $10 \mathrm{ng} / \mathrm{mL}$ IL-15, at an initial concentration of $5 \times 10^{5} / \mathrm{mL}$ in CTL medium $\left(1 \times 10^{6} \mathrm{~T}\right.$ cells per well of 24-well plates). Adenovirus (AdV) and CMV-specific cell lines were established using a similar protocol, but substituting AdV hexon (P36849), AdV penton (P12538), CMV pp65 (P06725) and CMV IE-1 (P13202) pepmixes (JPT Technologies) for those of E6 and E7.

\section{B-cell blast (BB) generation}

The epithelial cell line MRC5 (ATCC, Manassas, VA) was transduced with a retrovirus encoding CD154 (CD40L), as previously described. ${ }^{19}$ The transduced cell line was seeded at 50,000-100,000 per well of 24-well plate. When confluent or near-confluent, these cells were irradiated (20 Gy). PBMCs or CD14-negative PBMCs were suspended in CTL medium ( $1-2 \times 10^{5}$ cells $/ \mathrm{mL}$ ) with $100 \mathrm{U} / \mathrm{mL}$ of IL-4 and $1 \mu \mathrm{g} / \mathrm{mL}$ cyclosporin A (Sandoz, Holzkirchen, Germany) and plated over the MRC5-CD40L monolayer at $1-2 \times 10^{5}$ cells per well, with the medium replenished as needed. The resulting activated B cells (BB) were collected 7 days after initial culture, resuspended in CTL medium $\left(4 \times 10^{5} / \mathrm{mL}\right)$ and further expanded by weekly plating on fresh MRC5-CD40L irradiated monolayers at $4 \times 10^{5}$ per well. BB were loaded with pepmixes as described for DCs and used as APCs for the third and subsequent weekly $\mathrm{T}$ cell stimulations.

\section{Phytohemagglutinin (PHA) blast generation}

PBMCs were suspended at $5 \times 10^{5}$ cells $/ \mathrm{mL}$ in complete medium (RPMI 1640 supplemented with $10 \%$ human $\mathrm{AB}$ serum and $2 \mathrm{mM}$ alanyl-glutamine) with $5 \mu \mathrm{g} / \mathrm{mL}$ PHA (Sigma, Saint Louis, MO), and cultured in wells of 24-well plates $\left(1 \times 10^{6}\right.$ cells per well). After 48 to 72 hours, half of the medium was exchanged for fresh complete medium and IL-2 was added at a final concentration of $100 \mathrm{U} / \mathrm{mL}$. This process was repeated twice every 48 hours and the cells were subcultured into separate wells if the number of cells per well exceeded $2 \times 10^{6}$ cells. The PHA blasts were harvested, pooled and counted 8 days after initial culture and frozen in aliquots of $5 \times 10^{6}$ cells. One to three days before being used in a cytotoxicity assay, PHA blasts were thawed, washed twice in complete medium and resuspended at $5 \times 10^{5}$ cells/ $\mathrm{mL}$ in complete medium with $100 \mathrm{U} / \mathrm{mL}$ of IL- 2 and plated in 24 -well plates $\left(1 \times 10^{6}\right.$ cells per well). PHA blasts were loaded with pepmixes as described for DCs and used as APCs, or targets in ELISpot or cytotoxicity assays.

\section{Immunophenotyping}

Phycoerythrin (PE), fluorescein isothiocyanate (FITC), peridinin chlorophyll protein (PerCP) or allophycocyanin (APC)-conjugated CD3, CD4, CD8, CD19, CD27, CD28, CD56, CD45, CD45RA, CD45RO, CD62L, CD80, CD83, CD86, HLA-DR, CCR7 and HLA-A2 monoclonal antibodies were used to stain DCs, T cell lines, BB and PHA blasts, as appropriate. All antibodies were from Becton Dickinson-Pharmingen (San Diego, CA). Control samples labeled with an appropriate isotype-matched antibody were included in each experiment. Cells were analyzed by a flow cytometer (FACScan, Becton Dickinson) equipped with a filter set for 4 fluorescence signals. 


\section{ELISpot assays}

Interferon-gamma (IFN $\gamma$ ) ELISpot analysis was used to quantify HPV-specific T cells. PBMCs or T-cell lines were diluted to between $5 \times 10^{4}$ and $2 \times 10^{5}$ cells/well of $96-$ well plates, and we measured the number of T cells that secreted IFN $\gamma$ in response to stimulation with E6 or E7 pepmixes, peptide pools or single peptides. Each culture condition was tested in duplicate. Both negative (no-peptide) and positive (staphylococcal enterotoxin B) controls were included in each experiment. Pepmixes for survivin (O15392), EBV latent membrane protein 1 (LMP-1, P03230) and HIV group-specific antigen (Gag, multiple isolates) were used as specificity controls. In some experiments, the T-cell lines were also stimulated with autologous PHA blasts transduced with a retrovirus encoding E6-green fluorescent protein (GFP) or E7-GFP fusion proteins. After 20 hours of incubation, plates were developed for IFN $\gamma^{+}$spots as previously described, ${ }^{20}$ dried overnight at room temperature in the dark, and sent to ZellNet Consulting (New York, NY) for quantification. The frequency of T cells specific to each antigen was expressed as specific spot-forming cells (SFCs) per input cell number. ELISpot responses were considered positive when they were at least 10 SFCs per 100,000 cells assayed and more than twice the number in negative control cultures.

\section{TCR-V $\beta$ typing assays}

To analyze the repertoire of TCR V $\beta$ chain of the T cell lines, we used a flow cytometric assay (IOTest Beta Mark, Immunotech SAS, Marseille, France) as per manufacturer's instructions. This analysis detects $>70 \%$ of the normal human TCR V $\beta$ repertoire.

\section{Cytotoxicity assays}

The cytotoxic specificity of each $\mathrm{T}$ cell line was measured in a standard 4- to 6-hour chromium-51 $\left({ }^{51} \mathrm{Cr}\right)$ release assay, using effector-to-target (E:T) ratios of 40:1, 20:1, 10:1, and 5:1. Target cells were autologous PHA blasts or BB loaded with pepmixes. Allogeneic or autologous PHA blasts or BB alone were used as controls. The target cells were labeled simultaneously for 1 hour with ${ }^{51} \mathrm{Cr}$. The percentage of specific lysis was calculated as [(experimental release - spontaneous release)/(maximum release - spontaneous release) $] \times$ 100.

\section{Intracellular cytokine staining assays}

$\mathrm{T}$ cell lines were diluted to between $2 \times 10^{5}$ and $1 \times 10^{6}$ cells/well of $96-$ well plates, and virusspecific activity of responder cells was again measured after direct stimulation with E6 or E7 pepmixes. After overnight incubation in the presence of monensin and brefeldin A (Becton Dickinson-Pharmingen), T cells were stained with CD3 and CD8 (or CD4) antibodies, permeabilized, and stained with FITC- or PE-conjugated IFN $\gamma$ or TNFa antibodies (Becton Dickinson-Pharmingen).

\section{T-cell line and CaSki co-culture assays}

Co-cultures of T cell lines and an HPV16-positive, HLA-A2-positive tumor cell line (CaSki) were obtained by mixing virus (HPV16 or AdV/CMV)-specific T cells with CaSki cells in multiple E:T cell ratios (to a final relative proportion of $1 \%, 5 \%$ and $10 \%$ CaSki cells) in CTL medium. After the cells were combined, an aliquot stained with CD3 and CD45 antibodies was analyzed by flow cytometry to quantify the baseline proportion of CaSki (doubly CD3- and CD45-negative cells) among all cells. The cell mixtures were then plated in replicate wells of 24-well plates $\left(1 \times 10^{6}\right.$ cells/well). After 1 and 4 days of incubation, a portion of the wells were trypsinized and the cells stained and analyzed by flow cytometry. Expansion/contraction of tumor cell numbers was assessed as the percentage of CaSki cells in culture at each time point normalized to time zero. 


\section{Statistical analysis}

All numerical data are represented as mean \pm 1 standard deviation. Fisher's exact test or Student's t-test were used to determine the statistical significance of differences between groups for categorical and continuous variables, respectively, with a significance level a set at 0.05 .

\section{Results}

\section{Frequency of HPV16 E6- and E7-specific T cells in healthy individuals and in patients with HPV-associated cancers}

To investigate the presence of HPV16 E6- and E7-specific (E6/7-specific) T cells in the peripheral blood of healthy individuals and HPV-associated cancer patients, we synthesized a panel of peptides (15-mers overlapping by 11 amino acids [aa]) covering the 158 and 98 aa unique sequences of the E6 and E7 HPV16 proteins, respectively. These E6 and E7 peptide mixtures (pepmixes), comprising all possible HLA class I-restricted epitopes and many HLA class II-restricted epitopes for each antigen, were added to mononuclear cells isolated directly from peripheral blood. The number of IFN $\gamma$-positive spot-forming cells (SFCs) was then measured as described in Methods. We found no evidence for E6/E7-reactive T cells in any individual in either the normal or patient groups. This absence of reactivity could be due to true non-responsiveness of $\mathrm{T}$ cells (because of the non-existence of $\mathrm{T}$ cells bearing TCRs recognizing E6 or E7 epitopes or their polarization towards a non- $\mathrm{T}_{\mathrm{H}} 1$ population), or to the insensitivity of the ELISpot method to a low, but finite frequency of E6/E7-reactive precursor T cells. To distinguish these possibilities, we stimulated PBMCs with E6 and E7 peptide-loaded DCs, a strategy that has previously allowed us to expand and thus detect low frequency $\mathrm{T}$ cells specific for other viral antigens. ${ }^{20}$ Even under these conditions, however, no SFCs to E6/E7 were detected.

Since $50 \%$ to $>75 \%$ of cervical and oropharyngeal cancers, respectively, are associated with HPV16, this consistent lack of response even from patients with these tumors cannot be explained simply by lack of exposure to antigen in vivo. ${ }^{4}$ This assertion is further supported by our detection of HPV16 DNA in the tumors of 23 out of the 28 patients for which paraffin-embedded biopsy material was available. We reasoned instead that HPV-specific T cells from patients with HPV-associated cancers are anergized by their tumors and could therefore be "recovered" by more potent antigen presenting strategies, unless they happen to be physically deleted during $\mathrm{T}$ cell ontogeny in these patients. We therefore incorporated the cytokines IL-6, -7, -12 and -15 into the DC/T cell/pepmix cultures. This strategy enabled us to detect an E6 or E7 reactive population in 50\% of cervical and $62 \%$ of oropharyngeal cancer patients (Fig. 1), as well as in 1 of 20 normal subjects (not shown). E6/E7 reactivity, as defined in Methods, after 2 cycles of DC stimulation correlated with the presence of HPV16 DNA in the tumor sample (17/23 HPV16 ${ }^{+}$vs. $1 / 5$ HPV16 ${ }^{-}$samples, $\left.P=0.041\right)$. In addition, while there was a significant difference between SFCs in response to E6 or E7 versus the negative (no-peptide) control in cell lines from patients with HPV-positive tumors $(P=0.014$ and 0.027 , respectively), there was no significant difference in cell lines from patients with HPV-negative tumors ( $P=0.173$ and 0.511 , respectively). Of note, this difference was also significant for the HPV-indeterminate patients $(P=0.008$ and 0.044 , respectively) likely because more than two thirds of those are expected to have HPV16positive tumors. There was no correlation between tumor stage and amplitude of response. To investigate if endogenously processed viral antigens can be recognized by pepmixstimulated T cells, we tested their reactivity against autologous PHA blasts transduced with a retrovirus encoding the E6 or E7 antigen. We found that cell lines that produce IFN $\gamma$ in an ELISpot assay using E6 or E7 pepmix reacted identically against PHA blasts expressing E6 or E7, respectively (Fig. 1D-E). To confirm the antigenic specificity of the cell lines, we 
tested them in ELISpot assays against irrelevant peptides (EBV LMP-1, HIV Gag and survivin). There was no significant difference between SFCs in response to these peptides and to the negative (no-peptide) control ( $P=0.575,0.474$ and 0.593 , respectively, Fig. 1F). Hence, addition of appropriate cytokine combinations can selectively expand an HPV16specific population of T cells in individuals with HPV-associated cancers.

\section{Expansion of E6/7-specific T-cell lines for immunotherapy protocols}

To overcome reliance on multiple rounds of T-cell stimulation by DCs, which would often be unavailable in sufficient numbers to scale the approach for clinical use, we substituted activated B cells, or B-cell blasts (BB), as antigen presenting cells (APCs). We modified the previously described approaches ${ }^{21,22}$ by using a CD40L-transduced MRC5 feeder layer upon which PBMCs are grown in the presence of IL-4 and cyclosporine A. These conditions expand autologous B cells that express activation markers, including HLA-DR, CD80 and CD86 (Fig. 2A), and can be loaded with E6 and E7 pepmixes for use in weekly stimulation of HPV-specific T cells that have been initially activated by pepmix-loaded DCs. This strategy produced $>1200$ fold expansion of HPV-specific T-cell lines within 5 weeks (Fig. 2B), with an average $3.00 \pm 1.8$ (maximum 7.0) fold expansion per round of BB stimulation. Stimulation with BB induced both an increase in total cell numbers and a raise in the percentage of E6- and E7-specific T cells, demonstrating that expansion is antigen-specific (Fig. 2C).

\section{E6/7-specific T-cell lines include the CD4 and the CD8 subsets, are polyclonal and target specific epitopes}

Phenotypic analysis of the bulk cell lines showed that they were composed almost exclusively of T cells $\left(96.2 \pm 8.2 \% \mathrm{CD}^{+}\right.$cells $)$comprising a variable proportion of $\mathrm{CD}^{+}$ $(43.9 \pm 29.2 \%)$ and CD8+ cells $(42.7 \pm 27.1 \%)$, depending on the patient (Fig. 3A). These cells displayed a predominantly effector memory phenotype (CD45R0 ${ }^{+} \mathrm{CD}_{45 \mathrm{RA}^{-} \mathrm{CCR} 7^{-}}$ $\mathrm{CD}^{2} \mathrm{~L}^{-}$), but also included cells that expressed the memory/activation markers CD27 (28.4 $\pm 23.2 \%$, range 3 to $75 \%)$ and $\mathrm{CD} 28(64.4 \pm 14.1 \%$, range 51 to $88 \%)$. There were few $\mathrm{CD}^{-} \mathrm{CD}^{-} 6^{+}$natural killer (NK) cells $(2.5 \pm 7.5 \%$, median $0.5 \%)$. All lines expressed multiple T-cell receptor (TCR) V $\beta$ families, establishing their polyclonality (Fig. 3B).

We next characterized the epitope specificity of the E6/7-specific T cell lines. We combined the individual peptides into 12 (E6) and 9 (E7) pools, each containing 4 to 7 distinct peptides, such that each individual peptide was uniquely represented in 2 pools at most. Once reactivity was detected within a specific pair of peptide pools, each line was rescreened against the pertinent individual 15-mers, using individual peptides from nonreactive pools as negative controls (Fig. 4). This method revealed that multiple epitopes were recognized within the E6 and E7 antigens (Table 1) and showed that the presence of accessory cytokines did not result in non-specific activation of T cells. Since individual lines could recognize multiple epitopes of the same antigen or at least one epitope of each antigen, these studies confirmed that our lines were functionally, as well as phenotypically (Fig. 3B), polyclonal.

\section{Cytotoxic activity against autologous targets displaying E6/E7 antigens}

Although the cell lines we made consistently released IFN $\gamma$ in response to viral peptides (Figs. 2 and 3 ) and all contained CD8 ${ }^{+}$cells (12\%-98\%), only 7 of 25 tested T-cell lines were directly cytotoxic to pepmix-loaded autologous PHA blasts (or BBs) in short term chromium release assays (Fig. 5A). Killing was not increased by extending the assay to 6-8 hours. 


\section{Weakly-cytotoxic cell lines nonetheless release $T_{H} 1$ cytokines in the presence of autologous targets displaying E6/E7 antigens}

To investigate why several cell lines had weak cytotoxic activity in a chromium release assay, in contrast to the marked responses in ELISpot, we used intracellular staining for INF $\gamma$ and TNFa in the presence or absence of E6 or E7 pepmix stimulation to determine which cell subset was responsive to the antigens. We observed that most IFN $\gamma$ and/or $\mathrm{TNFa}$-positive cells were in the $\mathrm{CD} 4^{+}$compartment; few $\mathrm{CD}^{+} \mathrm{T}$ cells were cytokinepositive (Fig. 5B). In addition, there was no significant release of $\mathrm{T}_{\mathrm{H}} 2$ cytokines (Fig. 5C). Thus, the limited direct cytotoxicity of these cell lines likely represents predominant recognition of HPV antigens by CD4 $\mathrm{T}_{\mathrm{H}} 1$ cells.

\section{Partially HLA-matched HPV16-specific T-cell lines control tumor cell line growth in vitro}

To further investigate the potential antitumor activity of our HPV-directed lines, we cocultured HPV-specific T-cell lines from two HLA-A2-positive patients with an HLA-A2positive and HPV16-positive cervical cancer cell line (CaSki). The T-cell lines chosen recognize epitopes (E6 TIHDIILEC and E7 TLEDLLMGT) that are presumably restricted by HLA-A2 according to peptide prediction software (http://www-bimas.cit.nih.gov/molbio/ hla_bind/). These HPV16-specific T cells transiently control growth of CaSki cells (Fig. 5D), confirming their potential to react against HPV16-positive tumors, even when recognition occurs at a single HLA-restricted locus.

\section{Discussion}

We have established that HPV16 E6/E7-specific T cell lines can consistently be expanded from the blood of patients with HPV16-associated tumors through a scalable, GMPcompliant technique using specific accessory cytokines (IL-6, -7 -12 and -15), DCs and activated B cells. Although we could not confirm if tumors were positive for HPV16 in all patients, several studies have shown that the prevalence of HPV16 in cervical cancer and in the specific types of head and neck cancer we studied (oropharyngeal and base of the tongue) is at least $50 \%$ and $75 \%,{ }^{4}$ respectively. Moreover, even when we exclude patients of unknown tumor status and limit our analysis to the known positive and negative cases, our data still strongly support a difference in the pattern of $\mathrm{T}$ cell responses between HPV16positive and negative tumor patients. Therefore, we believe the T-cell lines expanded represent true immune responses against viral antigens.

Our data show that these lines may be grown to clinically useful numbers and possess the desirable characteristics of multiple T-cell subset representation (including the memory compartment) and a $\mathrm{T}_{\mathrm{H}} 1$ bias. Our results demonstrate that these lines comprise polyclonal populations of cells that react with multiple E6/E7 epitopes and, therefore, must contain polyspecific polyclonal effector cells. Although individual generation and specificity analysis of multiple clones would provide more extensive data on the components of this clonal response, it would not change this conclusion.

Current cure rates for HPV-associated tumors of the cervix and oropharynx are lower than desired and recurrent disease has a dismal prognosis. ${ }^{10,11}$ Although HPV-associated tumors express the viral E6 and E7 antigens, the patients' immune responses against virus-infected cells are limited in extent and efficacy. While immunization with E6 and E7 peptides may result in regression of HPV-associated pre-cancerous lesions in up to $47 \%$ of individuals, ${ }^{31}$ efforts to actively immunize patients whose infection has progressed to cancer have failed to generate significant anti-tumor activity. ${ }^{12-15}$ This is remarkable given the significant viral antigen exposure, but is consistent with the observation by many groups that HPV-specific circulating $\mathrm{T}$ cells are present at low to undetectable numbers in these patients. ${ }^{32}$ It is 
noteworthy that a similar lack of effective anti-tumor immunity is observed in subjects with EBV-associated malignancies, in whom naturally occurring $T$ cells with specificities to the virus-derived antigens LMP-1 and -2 are unable to control or eradicate lymphoma or nasopharyngeal cancer. In these patients, nevertheless, autologous EBV-specific CTLs can be generated ex vivo ${ }^{33}$ and infusion of even small numbers of such cells can produce complete and sustained remission. ${ }^{34}$ We have now demonstrated that it will be feasible to test a similar approach in patients with HPV-positive cancers.

Poor T-cell responses to HPV antigens in vivo may be due to failure of antigen presentation (due to inadequate antigen processing or lack of costimulation by APCs), inadequate trafficking of effector cells to tumor sites, or polarization of the immune response from effector to regulatory subsets. These adverse effects on immunity may be reversed in vitro and we have previously observed that the addition of accessory cytokines to T-cell and DC co-cultures allows the emergence of $\mathrm{T}$ cell responses against poorly immunogenic targets. The combination of cytokines used for this purpose (IL-6, -7, -12, -15) was chosen based on the complementary nature of their activities, and was validated empirically. IL-6 inhibits the conversion of progenitor cells to regulatory T-lymphocytes ${ }^{17}$ and IL-7 prevents activation induced cell death, ${ }^{35}$ both of which are likely important in this setting. IL-12 induces $\mathrm{T}_{\mathrm{H}} 1$ responses and enhances the cytotoxicity of CD8-positive T cells ${ }^{36}$ while IL-15 rescues anergic $\mathrm{T}$ cells and restores their activity against tumor associated antigens. ${ }^{16}$ Hence, the addition of these cytokines to our cultures allowed us to expand and activate $\mathrm{T}$ cells that were low in frequency and likely anergic.

We used pepmixes and specific cytokines to generate the E6/E7-specific T cell lines from cancer patients, but other investigators have exploited the IFN $\gamma$-capture method to rapidly select and enrich for E6-specific T cells after stimulation of PBMCs with long peptides. ${ }^{25}$ However, in contrast to our approach, these lines were generated from virus-exposed healthy donors who would be HLA-disparate from the cancer patients requiring therapy if adoptive transfer were planned. Moreover, these cell lines were grown using "T cell growth factor", a poorly defined source of cytokines that cannot readily be made GMP-compliant or scaled.

We measured the antitumor activity of our cell lines by using autologous targets that were pulsed with the relevant antigens. Although a co-culture with HPV16-positive tumor targets would be optimal, those assays cannot be readily established for the majority of patients since there are no syngeneic (or HLA-matched) tumor cell lines available. In our assays, only a minority of our cell lines were directly cytotoxic to E6/E7-peptide-pulsed target cells, likely because the majority of HPV-reactive cells in our expanded cell lines were $\mathrm{CD} 4^{+}$ rather than $\mathrm{CD}^{+}$cytotoxic effector cells. Nonetheless, even though $\mathrm{CD} 8^{+}$cells may be the immediate effectors of tumor cell destruction after TCR engagement, virus/tumor specific $\mathrm{CD} 4^{+}$cells also play an important role, both by providing helper activities to $\mathrm{CD} 8^{+}$and by their own, more delayed, cytotoxic activity. ${ }^{37}$ Indeed, we have previously observed significant clinical anti-tumor and antiviral responses after administration of predominantly $\mathrm{CD} 4^{+} \mathrm{EBV}$ or adenovirus-specific lines to patients with EBV-positive lymphoma or adenoviral infection, ${ }^{18,38}$ and the mechanisms for these effects and for the synergy between $\mathrm{CD}^{+}$and $\mathrm{CD} 4^{+} \mathrm{T}$ cells have been dissected in murine models. ${ }^{39}$

Even though E6/7-specific T cells may directly or indirectly clear tumor cells expressing viral derived antigens, one concern about the adoptive transfer approach is that these $\mathrm{T}$ cells may nonetheless become inactive or be eliminated in vivo, since they will be re-exposed to the same hostile microenvironment that prevented their spontaneous emergence. The immune evasion strategies of viruses and tumors include the production of cytokines that inhibit the activity and proliferation of effector cells. One widely used mechanism is secretion of transforming growth factor beta (TGF $\beta$ ), a ubiquitous cytokine with pleiotropic 
effects on cell growth and differentiation that plays a significant role in maintaining T-cell homeostasis by inhibiting $\mathrm{T}$ cell proliferation ${ }^{40}$ Progression of pre-malignant lesions associated with HPV16 infection, such as cervical intraepithelial neoplasia, results in the increased expression of TGF $\beta-1$ (one of the TGF $\beta$ isoforms), among other immunosuppressive cytokines. ${ }^{41}$ TGF $\beta-1$ may also derive from Tregs and these are significantly increased in draining lymph nodes of patients with advanced cervical cancer ${ }^{42}$ and in the circulation of head and neck cancer patients. ${ }^{43}$ We have genetically modified CTLs ex vivo to render them resistant to the immune inhibitory effects of TGF $\beta-1$ and, if necessary, this strategy could be applied to our E6/7-specific cell lines. ${ }^{34,44}$

In addition to negative growth and survival signals, the effectiveness of adoptively transferred virus-specific CTLs may also be limited by their poor capacity to expand in vivo. ${ }^{45}$ Systemic administration of cytokines such as IL-2 may enhance the survival of transferred antigen-specific CTLs, but can be associated with serious side effects, limiting the amount and duration of treatment. ${ }^{46}$ Moreover, IL-2 favors the expansion of unwanted cell subsets such as Tregs, which also express the IL-2Ra, and adversely affect the function of CTLs. ${ }^{47}$ By contrast, other cytokines, such as IL-15, play an essential role in homeostatic expansion of $\mathrm{T}$ cells, including memory $\mathrm{CD}^{+}$cells, ${ }^{48}$ and accelerate immune reconstitution in a mouse model, ${ }^{49}$ while decreasing the number of Tregs by inducing their apoptosis. ${ }^{50}$ Co-administration of this cytokine may thus also protect E6/7-specific cells from inhibitory effects of the tumor microenvironment.

We believe that our cell generation procedure has the potential to be the foundation of clinical trials evaluating virus-specific T cells as therapy for HPV-associated tumors. If successful, similar strategies may be beneficial for other tumors expressing non-viral tumor associated antigens.

\section{Acknowledgments}

This work was supported in part by a Developmental Research Program Award (C.A.R., E.M.S.) from the UTMDACC Head and Neck NCI SPORE P50 CA097007 (Lippman, Vu, Meyers) and a Pilot Program Grant from the Ovarian Cancer Research Fund (M.L.A.). C.A.R. is a recipient of a Career Development Award from the Conquer Cancer Foundation of the American Society of Clinical Oncology.

\section{References}

1. D'Souza G, Kreimer AR, Viscidi R, et al. Case-control study of human papillomavirus and oropharyngeal cancer. N Engl J Med. 2007; 356:1944-1956. [PubMed: 17494927]

2. Furniss CS, McClean MD, Smith JF, et al. Human papillomavirus 16 and head and neck squamous cell carcinoma. Int J Cancer. 2007; 120:2386-2392. [PubMed: 17315185]

3. Gillison ML, Koch WM, Capone RB, et al. Evidence for a causal association between human papillomavirus and a subset of head and neck cancers. J Natl Cancer Inst. 2000; 92:709-720. [PubMed: 10793107]

4. Psyrri A, DiMaio D. Human papillomavirus in cervical and head-and-neck cancer. Nat Clin Pract Oncol. 2008; 5:24-31. [PubMed: 18097454]

5. Syrjanen S. Human papillomaviruses in head and neck carcinomas. N Engl J Med. 2007; 356:19931995. [PubMed: 17494934]

6. zur Hausen H. Papillomaviruses and cancer: from basic studies to clinical application. Nat Rev Cancer. 2002; 2:342-350. [PubMed: 12044010]

7. Hoots BE, Palefsky JM, Pimenta JM, et al. Human papillomavirus type distribution in anal cancer and anal intraepithelial lesions. Int J Cancer. 2009; 124:2375-2383. [PubMed: 19189402]

8. Miralles-Guri C, Bruni L, Cubilla A, et al. HPV prevalence and type distribution in penile carcinoma. J Clin Pathol. 2009 
9. Jemal A, Siegel R, Ward E, et al. Cancer statistics, 2009. CA Cancer J Clin. 2009; 59:225-249. [PubMed: 19474385]

10. Forastiere AA, Ang KK, Brizel D, et al. Head and neck cancers. J Natl Compr Canc Netw. 2008; 6:646-695. [PubMed: 18691457]

11. Greer BE, Koh WJ, Abu-Rustum N, et al. Cervical cancer. J Natl Compr Canc Netw. 2008; 6:1436. [PubMed: 18267056]

12. Doorbar J. Papillomavirus life cycle organization and biomarker selection. Dis Markers. 2007; 23:297-313. [PubMed: 17627064]

13. Stanley MA, Pett MR, Coleman N. HPV: from infection to cancer. Biochem Soc Trans. 2007; 35:1456-1460. [PubMed: 18031245]

14. Kenter GG, Welters MJ, Valentijn AR, et al. Phase I immunotherapeutic trial with long peptides spanning the E6 and E7 sequences of high-risk human papillomavirus 16 in end-stage cervical cancer patients shows low toxicity and robust immunogenicity. Clin Cancer Res. 2008; 14:169177. [PubMed: 18172268]

15. Welters MJ, Kenter GG, Piersma SJ, et al. Induction of tumor-specific CD4+ and CD8+ T-cell immunity in cervical cancer patients by a human papillomavirus type 16 E6 and E7 long peptides vaccine. Clin Cancer Res. 2008; 14:178-187. [PubMed: 18172269]

16. Teague RM, Sather BD, Sacks JA, et al. Interleukin-15 rescues tolerant CD8+ T cells for use in adoptive immunotherapy of established tumors. Nat Med. 2006; 12:335-341. [PubMed: 16474399]

17. Korn T, Mitsdoerffer M, Croxford AL, et al. IL-6 controls Th17 immunity in vivo by inhibiting the conversion of conventional T cells into Foxp3+ regulatory T cells. Proc Natl Acad Sci U S A. 2008; 105:18460-18465. [PubMed: 19015529]

18. Leen AM, Christin A, Myers GD, et al. Cytotoxic T lymphocyte therapy with donor T cells prevents and treats adenovirus and Epstein-Barr virus infections after haploidentical and matched unrelated stem cell transplantation. Blood. 2009; 114:4283-4292. [PubMed: 19700662]

19. Dotti G, Savoldo B, Yotnda P, et al. Transgenic expression of CD40 ligand produces an in vivo antitumor immune response against both CD40(+) and CD40(-) plasmacytoma cells. Blood. 2002; 100:200-207. [PubMed: 12070028]

20. Gerdemann U, Christin AS, Vera JF, et al. Nucleofection of DCs to generate Multivirus-specific T cells for prevention or treatment of viral infections in the immunocompromised host. Mol Ther. 2009; 17:1616-1625. [PubMed: 19584818]

21. von Bergwelt-Baildon MS, Vonderheide RH, Maecker B, et al. Human primary and memory cytotoxic T lymphocyte responses are efficiently induced by means of CD40-activated B cells as antigen-presenting cells: potential for clinical application. Blood. 2002; 99:3319-3325. [PubMed: 11964299]

22. Wiesner M, Zentz C, Mayr C, et al. Conditional immortalization of human B cells by CD40 ligation. PLoS One. 2008; 3:e1464. [PubMed: 18213373]

23. Thomas KJ, Smith KL, Youde SJ, et al. HPV16 E6 29-38-specific T cells kill cervical carcinoma cells despite partial evasion of T-cell effector function. Int J Cancer. 2008; 122:2791-2799. [PubMed: 18366058]

24. Bourgault Villada I, Moyal Barracco M, Berville S, et al. Human papillomavirus 16-specific T cell responses in classic HPV-related vulvar intra-epithelial neoplasia. Determination of strongly immunogenic regions from E6 and E7 proteins. Clin Exp Immunol. 2010; 159:45-56. [PubMed: 19843089]

25. de Jong A, van der Hulst JM, Kenter GG, et al. Rapid enrichment of human papillomavirus (HPV)specific polyclonal $\mathrm{T}$ cell populations for adoptive immunotherapy of cervical cancer. Int $\mathbf{J}$ Cancer. 2005; 114:274-282. [PubMed: 15540211]

26. Delgado FG, Martinez E, Cespedes MA, et al. Increase of human papillomavirus-16 E7-specific T helper type 1 response in peripheral blood of cervical cancer patients after radiotherapy. Immunology. 2009; 126:523-534. [PubMed: 18778290]

27. Nilges K, Hohn H, Pilch H, et al. Human papillomavirus type 16 E7 peptide-directed CD8+ T cells from patients with cervical cancer are cross-reactive with the coronavirus NS2 protein. J Virol. 2003; 77:5464-5474. [PubMed: 12692247] 
28. Riemer AB, Keskin DB, Zhang G, et al. A conserved E7-derived cytotoxic T lymphocyte epitope expressed on human papillomavirus 16-transformed HLA-A2+ epithelial cancers. J Biol Chem. 2010; 285:29608-29622. [PubMed: 20615877]

29. Wang X, Moscicki AB, Tsang L, et al. Memory T cells specific for novel human papillomavirus type 16 (HPV16) E6 epitopes in women whose HPV16 infection has become undetectable. Clin Vaccine Immunol. 2008; 15:937-945. [PubMed: 18448624]

30. Youde SJ, Dunbar PR, Evans EM, et al. Use of fluorogenic histocompatibility leukocyte antigenA*0201/HPV 16 E7 peptide complexes to isolate rare human cytotoxic T-lymphocyte-recognizing endogenous human papillomavirus antigens. Cancer Res. 2000; 60:365-371. [PubMed: 10667589]

31. Kenter GG, Welters MJ, Valentijn AR, et al. Vaccination against HPV-16 oncoproteins for vulvar intraepithelial neoplasia. N Engl J Med. 2009; 361:1838-1847. [PubMed: 19890126]

32. van der Burg SH, de Jong A, Welters MJ, et al. The status of HPV16-specific T-cell reactivity in health and disease as a guide to HPV vaccine development. Virus Res. 2002; 89:275-284. [PubMed: 12445667]

33. Gottschalk S, Edwards OL, Sili U, et al. Generating CTLs against the subdominant Epstein-Barr virus LMP1 antigen for the adoptive immunotherapy of EBV-associated malignancies. Blood. 2003; 101:1905-1912. [PubMed: 12411306]

34. Bollard CM, Gottschalk S, Leen AM, et al. Complete responses of relapsed lymphoma following genetic modification of tumor-antigen presenting cells and T-lymphocyte transfer. Blood. 2007; 110:2838-2845. [PubMed: 17609424]

35. Vella A, Teague TK, Ihle J, et al. Interleukin 4 (IL-4) or IL-7 prevents the death of resting T cells: stat6 is probably not required for the effect of IL-4. J Exp Med. 1997; 186:325-330. [PubMed: 9221762]

36. Indrova M, Bieblova J, Rossowska J, et al. HPV 16-associated tumours: IL-12 can repair the absence of cytotoxic and proliferative responses of tumour infiltrating cells after chemotherapy. Int J Oncol. 2009; 34:173-179. [PubMed: 19082488]

37. Hombach A, Kohler H, Rappl G, et al. Human CD4+ T cells lyse target cells via granzyme/ perforin upon circumvention of MHC class II restriction by an antibody-like immunoreceptor. J Immunol. 2006; 177:5668-5675. [PubMed: 17015756]

38. Heslop HE, Slobod KS, Pule MA, et al. Long-term outcome of EBV-specific T-cell infusions to prevent or treat EBV-related lymphoproliferative disease in transplant recipients. Blood. 2010; 115:925-935. [PubMed: 19880495]

39. Cheadle EJ, Hawkins RE, Batha H, et al. Eradication of established B-cell lymphoma by CD19specific murine $\mathrm{T}$ cells is dependent on host lymphopenic environment and can be mediated by CD4+ and CD8+ T cells. J Immunother. 2009; 32:207-218. [PubMed: 19242379]

40. Bollard CM, Rossig C, Calonge MJ, et al. Adapting a transforming growth factor beta-related tumor protection strategy to enhance antitumor immunity. Blood. 2002; 99:3179-3187. [PubMed: 11964281]

41. Giannini SL, Al-Saleh W, Piron H, et al. Cytokine expression in squamous intraepithelial lesions of the uterine cervix: implications for the generation of local immunosuppression. Clin Exp Immunol. 1998; 113:183-189. [PubMed: 9717966]

42. van der Burg SH, Piersma SJ, de Jong A, et al. Association of cervical cancer with the presence of CD4+ regulatory T cells specific for human papillomavirus antigens. Proc Natl Acad Sci U S A. 2007; 104:12087-12092. [PubMed: 17615234]

43. Strauss L, Bergmann C, Whiteside TL. Functional and phenotypic characteristics of CD4+CD25highFoxp3+ Treg clones obtained from peripheral blood of patients with cancer. Int $\mathbf{J}$ Cancer. 2007; 121:2473-2483. [PubMed: 17691114]

44. Foster AE, Dotti G, Lu A, et al. Antitumor activity of EBV-specific T lymphocytes transduced with a dominant negative TGF-beta receptor. J Immunother. 2008; 31:500-505. [PubMed: 18463534]

45. Dudley ME, Wunderlich JR, Robbins PF, et al. Cancer regression and autoimmunity in patients after clonal repopulation with antitumor lymphocytes. Science. 2002; 298:850-854. [PubMed: 12242449] 
46. Dudley ME, Wunderlich JR, Yang JC, et al. A phase I study of nonmyeloablative chemotherapy and adoptive transfer of autologous tumor antigen-specific $\mathrm{T}$ lymphocytes in patients with metastatic melanoma. J Immunother. 2002; 25:243-251. [PubMed: 12000866]

47. Ahmadzadeh M, Rosenberg SA. IL-2 administration increases CD4+ CD25(hi) Foxp3+ regulatory T cells in cancer patients. Blood. 2006; 107:2409-2414. [PubMed: 16304057]

48. Ma A, Boone DL, Lodolce JP. The pleiotropic functions of interleukin 15: not so interleukin 2-like after all. J Exp Med. 2000; 191:753-756. [PubMed: 10704456]

49. Alpdogan O, Eng JM, Muriglan SJ, et al. Interleukin-15 enhances immune reconstitution after allogeneic bone marrow transplantation. Blood. 2005; 105:865-873. [PubMed: 15280205]

50. Strauss L, Bergmann C, Whiteside TL. IL-15 administration to human CD4+ T cells leads to expansion of CD4+CD25- cells but to a decrease of CD4+CD25highFoxp3+T cells via apoptosis. J Immunol. 2007; 178 S147-a- 

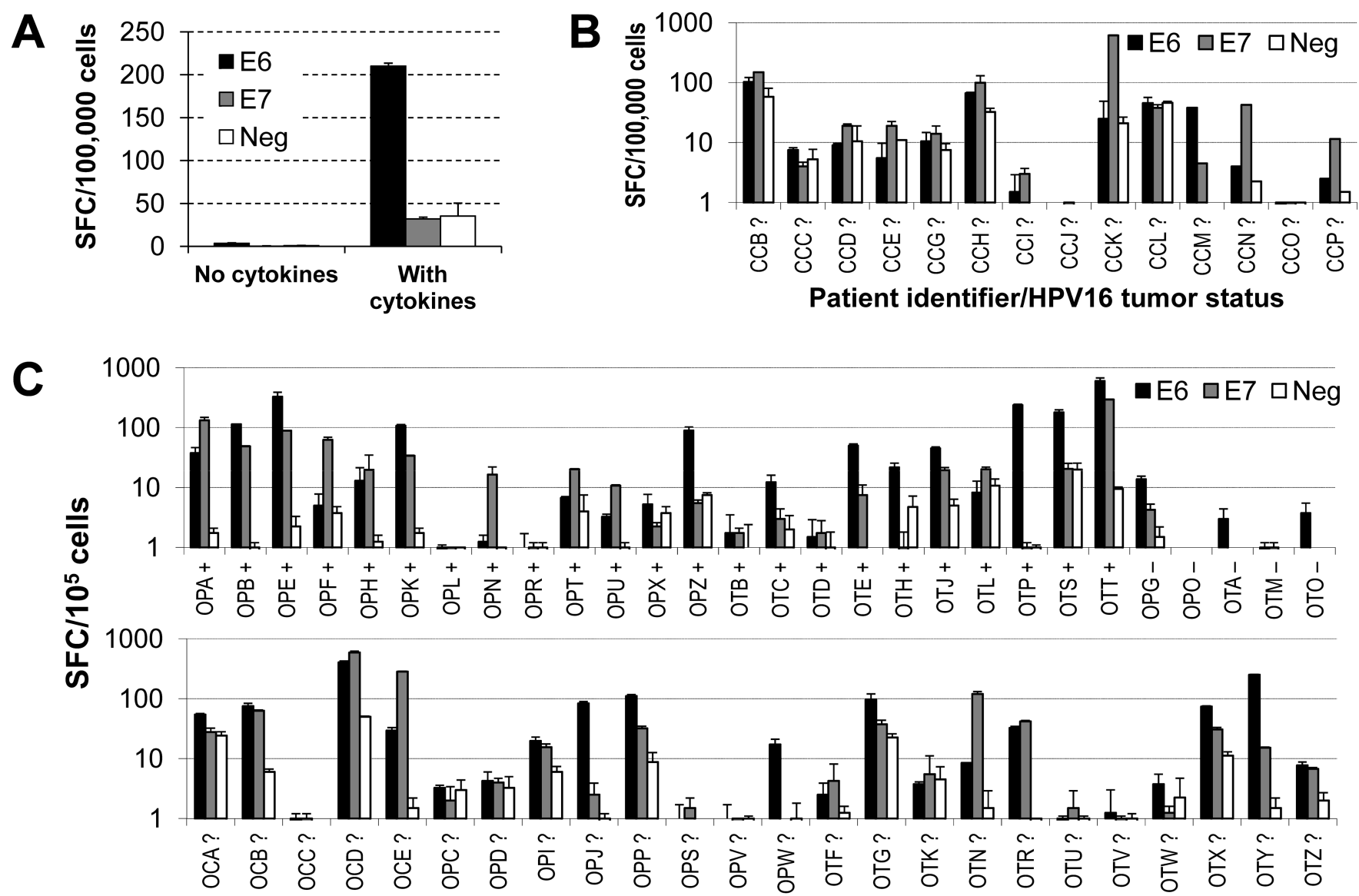

Patient identifier/HPV16 tumor status

D

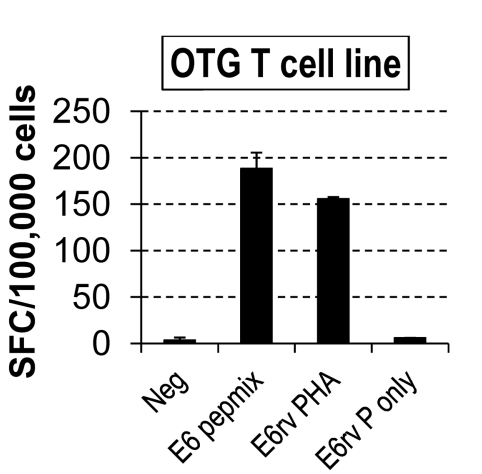

$\mathbf{E}$

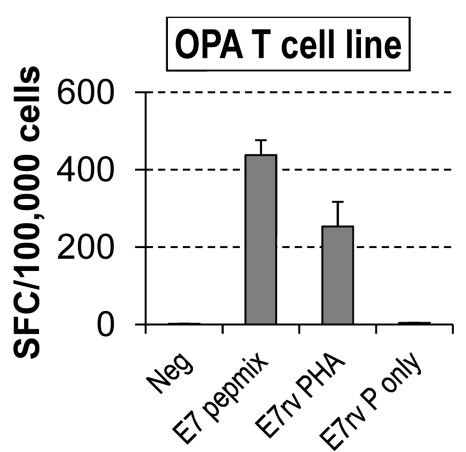

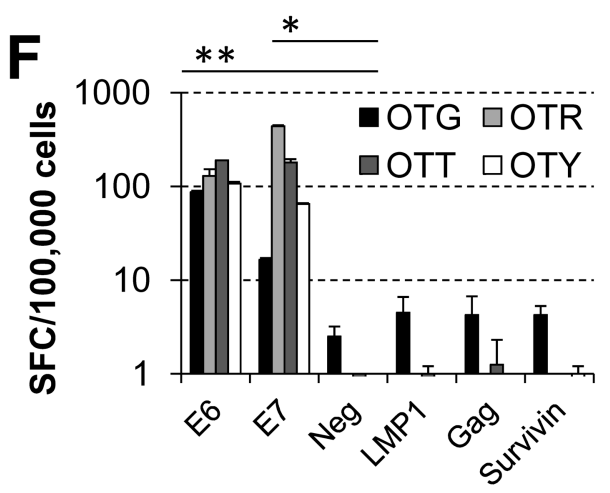

Figure 1. HPV16 E6/7-specific T cells can be expanded from the peripheral blood of patients with HPV16-associated cancers using autologous DCs

Patients PBMCs were stimulated twice with autologous DCs loaded with E6 and E7 pepmixes, with or without accessory cytokines (IL-6, -7, -12 and -15), and release of IFN $\gamma$ by the cultured cells was quantified by an ELISpot assay after a 24-h stimulation of the resulting lines with E6 or E7 pepmix in the absence of cytokines (SFC, spot forming cells; E6, E6 pepmix; E7, E7 pepmix; Neg, no-peptide control). (A) The presence of accessory cytokines is essential for the emergence of detectable $\mathrm{T}$ cell responses. The patient depicted (OPB) had most reactivity against E6. (B) Cell lines obtained from women with cervical cancer undergoing surgery for their tumors. HPV16-status of their tumors is unknown. (C) 
Cell lines obtained from patients with oropharyngeal cancer before receiving chemoradiation therapy for their malignancies. The top row shows patients for which the HPV16 status of tumors was determined (+ positive, - negative), whereas the bottom row corresponds to patients whose tumor status is unknown. Detection of responses correlates with HPV16 status of tumors. (D, E) HPV-specific T-cell lines obtained with pepmix stimulation are able to recognize endogenously processed E6 or E7 antigens (E6/7rv PHA, retrovirally transduced PHA blasts with E6/7; E6/E7rv P only, retrovirally transduced PHA blasts with E6/7 alone). (F) Irrelevant peptides do not elicit responses above those of nopeptide control, in contrast to those against E6 and E7 (illustrated for cell lines from patients OTG, OTR, OTT and OTY). 
A
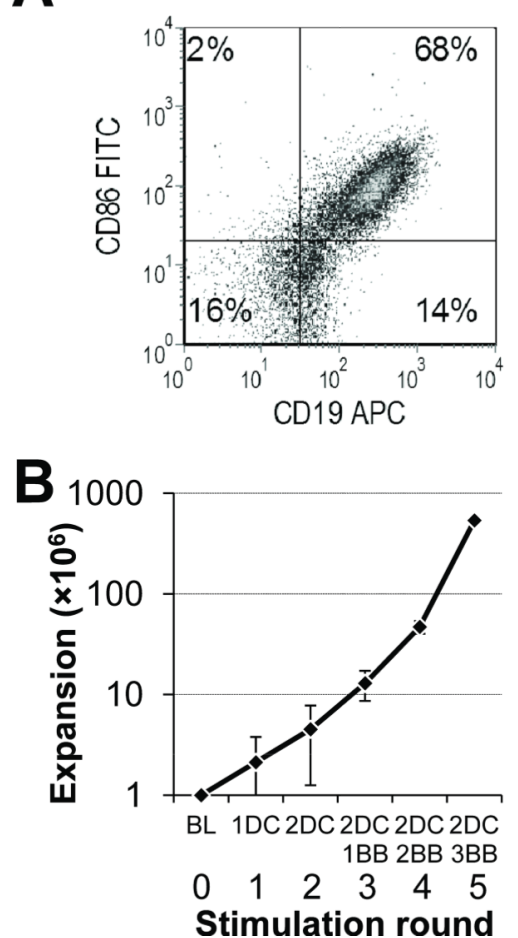

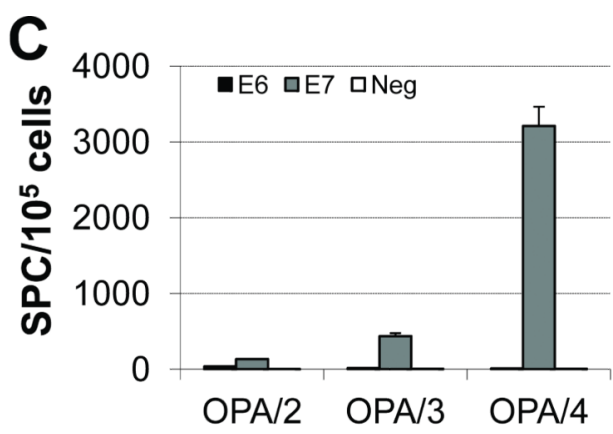

Patient ID/Stimulations

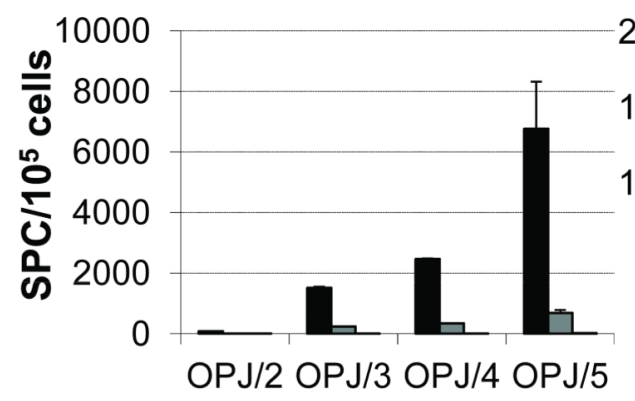

Patient ID/Stimulations

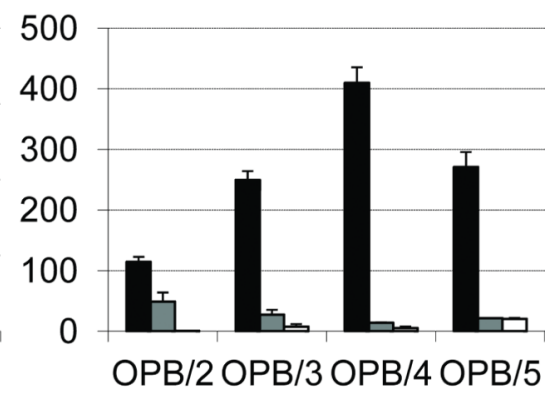

Patient ID/Stimulations

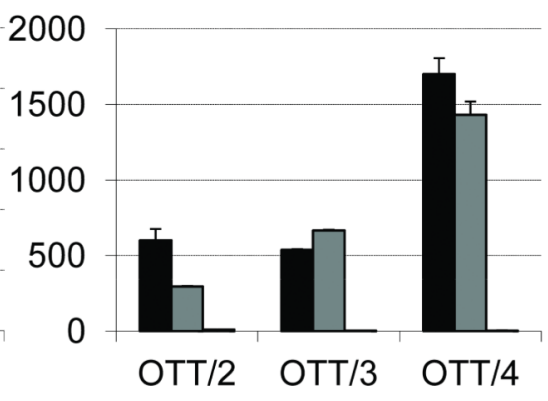

Patient ID/Stimulations

Figure 2. Autologous activated B cells, or B blasts (BB), can further selectively expand HPV16 E6/E7-specific cell lines

DC-expanded cell lines were further stimulated with autologous BBs loaded with E6 and E7 pepmixes, in the presence of IL-15, and release of IFN $\gamma$ by the cultured cells was again quantified by an ELISpot assay after a 24-h stimulation of the resulting lines with E6 or E7 pepmix in the absence of cytokines. (A) BB lines are predominantly composed of B cells with markers of activation, including CD86 (shown), CD80 and HLA-DR (not shown). (B) Average expansion of $22 \mathrm{HPV} 16$-specific T-cell lines, assuming a starting population of $1 \times 10^{6} \mathrm{PBMCs}$, with each successive round of stimulation $(0: \mathrm{BL}$, baseline; 1: 1DC, one round of DC stimulation; 2: 2DC, two rounds of DC stimulation; 3: 2DC 1BB, one round of $\mathrm{BB}$ after two rounds of DC stimulation; etc.). (C) The expanded cell lines have increased specificity for HPV16 antigens as demonstrated by an increased fraction of IFN $\gamma$-producing cells with each round of stimulation with autologous pepmix-loaded BBs. 

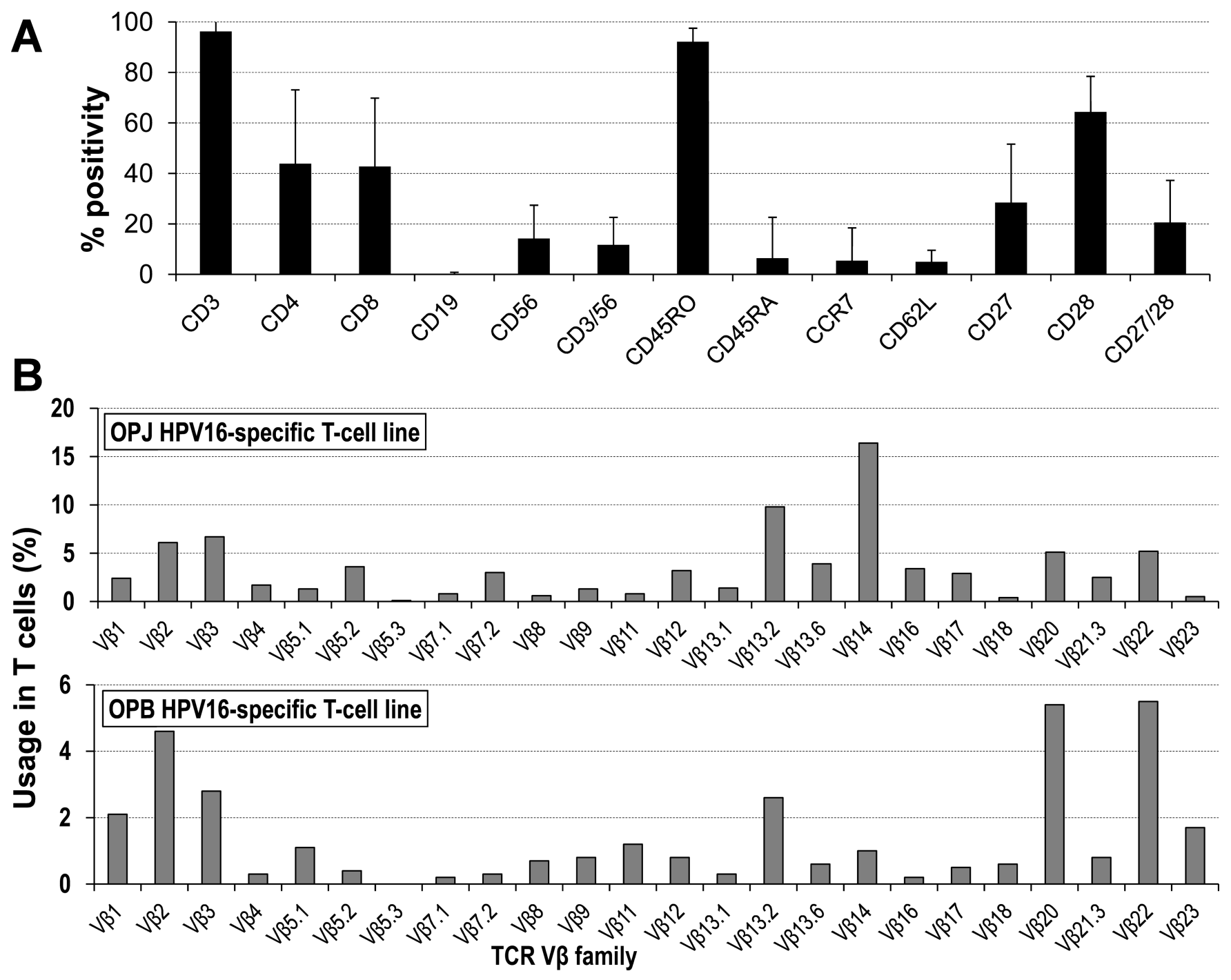

Figure 3. HPV16 E6/E7-specific cell lines comprise multiple T cell compartments and are polyclonal

(A) These cell lines are composed almost exclusively by $\mathrm{T}$ cells with a variable proportion of $\mathrm{CD}^{+}$and $\mathrm{CD} 8^{+}$cells, which have a predominantly effector memory phenotype. There is usually a small fraction of $\mathrm{T}$ cells positive for $\mathrm{CD} 56$, but almost no $\mathrm{CD} 3^{-} \mathrm{CD} 56^{+} \mathrm{NK}$ cells.

(B) V $\beta$ TCR typing demonstrates polyclonality (two representative examples shown). 

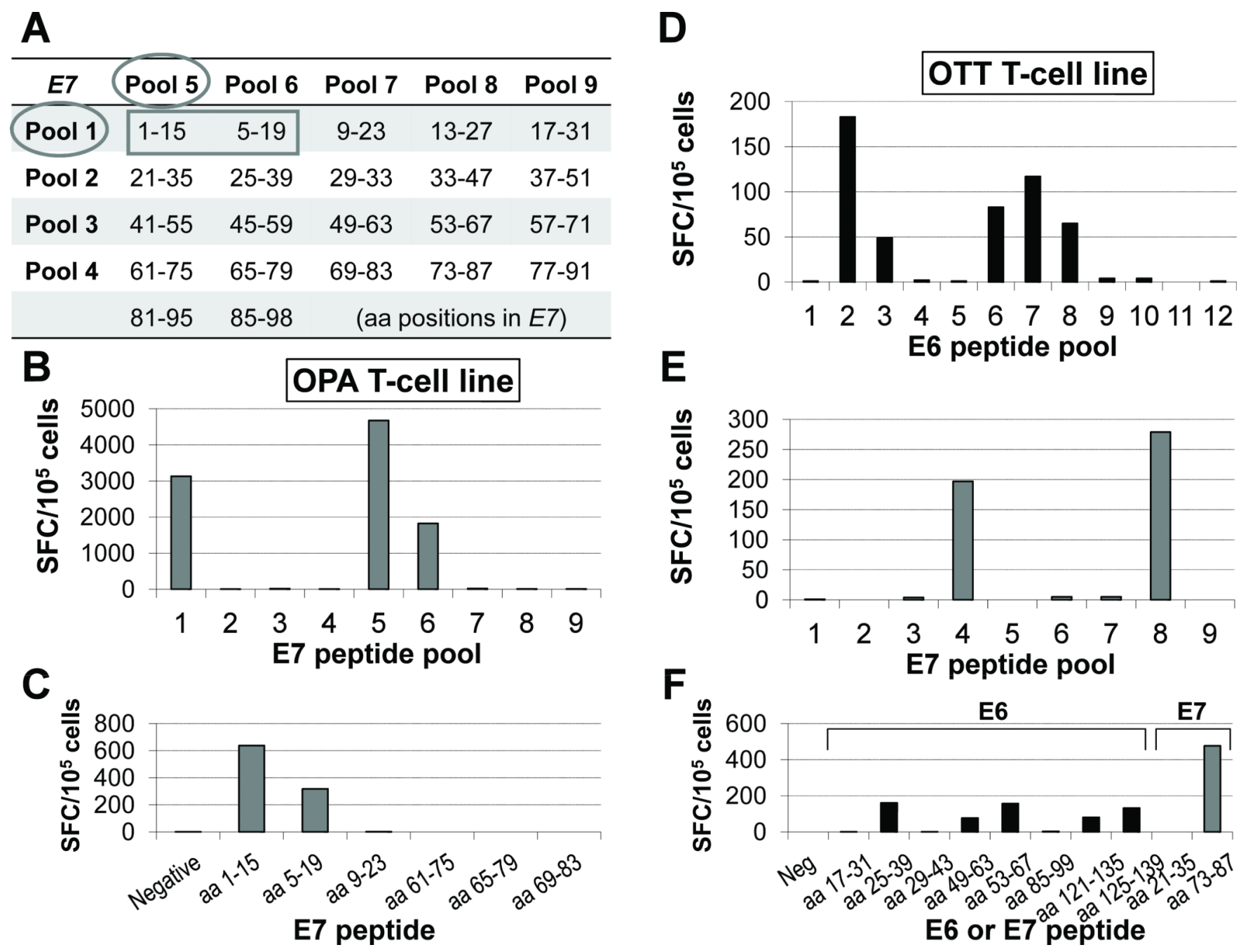

Figure 4. Strategy for mapping epitope sites identified by $\mathbf{T}$ cell lines

We combined the individual overlapping peptides spanning E6 or E7 (shown) into pools containing 4 to 7 distinct peptides, so that each individual peptide was represented in 2 of the pools (A). To pinpoint the peptide region containing the epitopes in question, once reactivity was detected within a specific pair of peptide pools $(\mathbf{B})$, each line (patient OPA shown in panels B and C) was rescreened against the pertinent individual 15-mers, using individual peptides from non-reactive pools as negative controls $(\mathbf{C})$. This method revealed that the putative epitopes are contained in particular regions of the antigens (aa 5-15 of E7 for OPA). This approach showed that individual lines could recognize multiple epitopes of the same antigen or at least one epitope of each antigen, confirming that our lines were functionally polyclonal. Another example (patient OTT) is shown in panels (D-F) for E6 pools, E7 pools and individual peptides, respectively. 

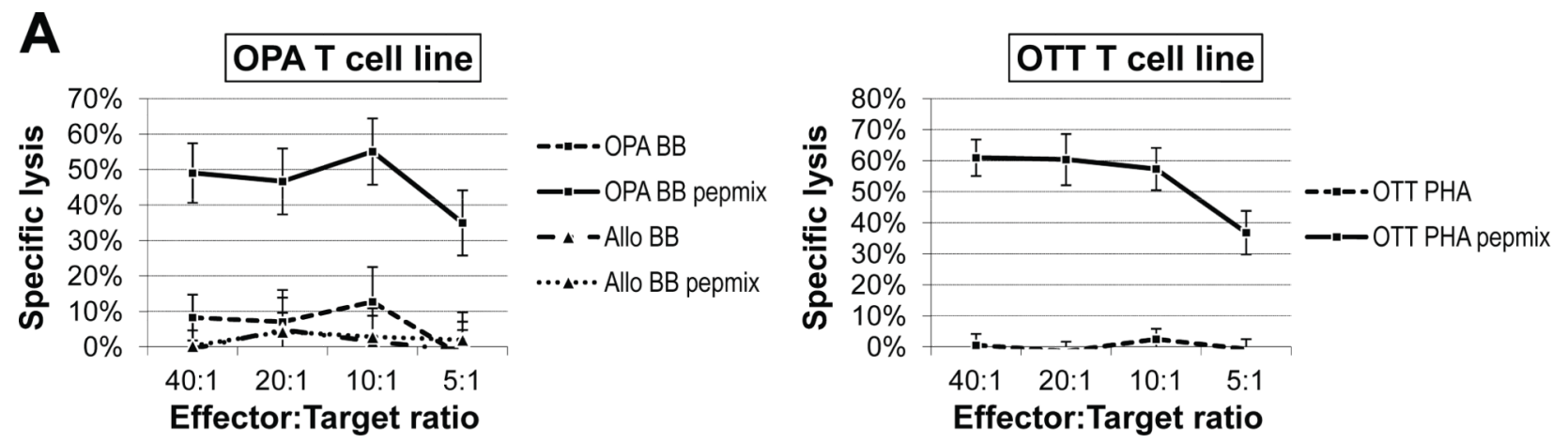

B
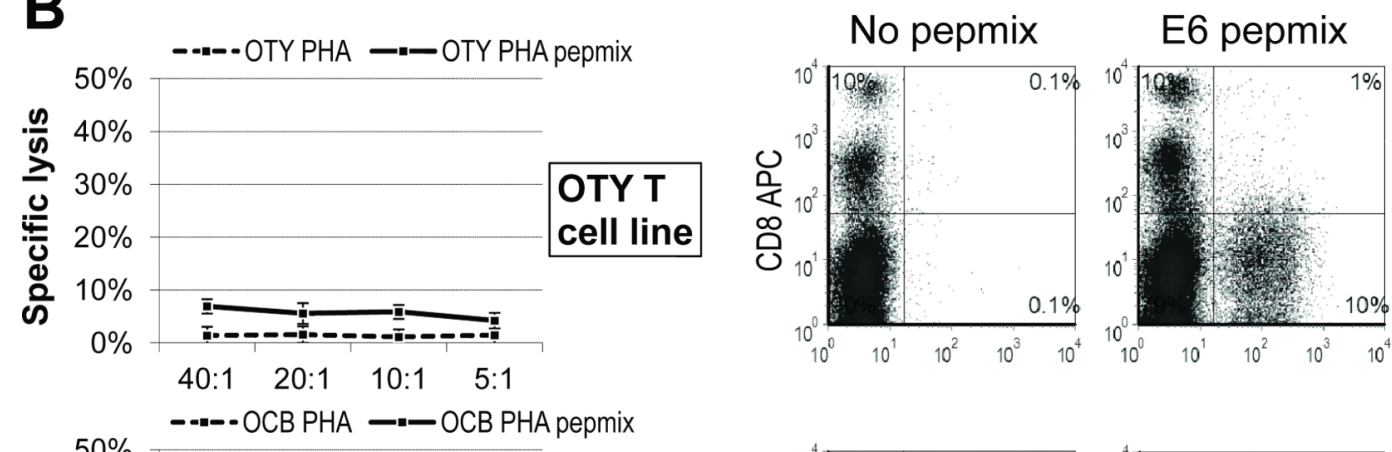

E7 pepmix
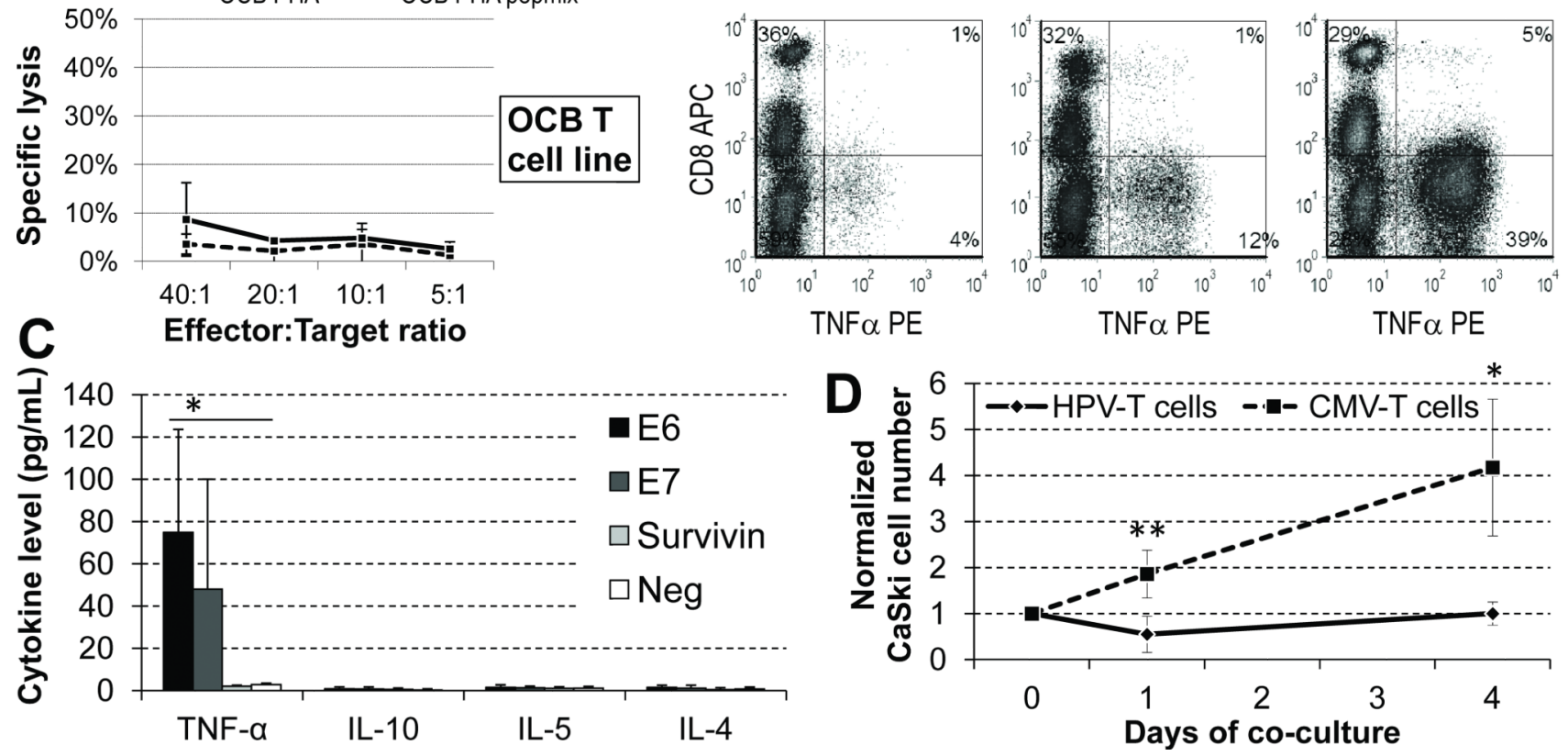

Figure 5. HPV16 E6/E7-specific T cells are cytotoxic against antigen-positive targets and/or release $T_{H} 1$ cytokines in response to antigen-positive targets

We performed a 4-hour chromium release assay against autologous targets (PHA blasts PHA - or B-blasts - BB) loaded with E6 and E7 pepmixes or irrelevant peptides. (A) In approximately one quarter of the cell lines there was robust differential killing of autologous targets displaying E6/E7 without allogeneic killing (shown for OPA). (B) Cell lines that were not cytotoxic in this assay produced $\mathrm{T}_{\mathrm{H}} 1$ cytokines ( $\mathrm{TNFa}$ shown) after exposure to the antigens, with this activity being mediated almost exclusively by CD4 cells. (C) Cell lines do not produce $\mathrm{T}_{\mathrm{H}} 2$ cytokines in response to E6 or E7 antigens ( $P=0.320$ for IL-10, 0.517 for IL-5 and 0.178 for IL-4 versus negative controls; $P=0.004$ for TNF-a). (D) 
HPV16-specific T cells from HLA-A2 positive donors achieve transient control of growth of CaSki, an HPV16 and HLA-A2 positive cervical cancer cell line $(P=0.008$ at day 1 and 0.022 at day 4, versus AdV/CMV-specific lines from the same donor). 


\section{Table 1}

Protein regions containing epitopes recognized by HVP16-specific T cell lines.

\begin{tabular}{llll}
\hline Antigen/Amino acid positions & Peptide sequence & HLA restriction & Previous reference* \\
\hline E6 aa $25-39$ & $\underline{\text { ELQTTIHDIILECVY }}$ & HLA-A2 & 23 \\
\hline E6 aa 53-63 & $\underline{\text { AFRDLCIVYRD }}$ & Unknown & 24 \\
\hline E6 aa 57-71 & LCIVYRDGNPYAVCD & Unknown & 24 \\
\hline E6 aa $93-107$ & $\underline{\text { TTLEQQYNKPLCDLL }}$ & Unknown & 25 \\
\hline E6 aa $125-135$ & $\underline{\text { HLDKKQRFHNI }}$ & Unknown & 25,29 \\
\hline E6 aa 129-139 & $\underline{\text { KQRFHNIRGRW }}$ & Unknown & 25,29 \\
\hline E6 aa 133-143 & $\underline{\text { HNIRGRWTGRC }}$ & Unknown & 25,29 \\
\hline E7 aa 5-15 & TPTLHEYMLDL & HLA-A2 & $27,28,30$ \\
\hline E7 aa 9-19 & HEYMLDLQPET & HLA-A2 & $27,28,30$ \\
\hline E7 aa $73-87$ & $\underline{\text { HVDIRTLEDLLMGTL }}$ & Unknown & 26 \\
\hline
\end{tabular}

The underlined portions are contained in peptide fragments against which $\mathrm{T}$ cell reactivity has been previously documented in the references provided. 